\title{
A Comparison of Data Analysis Methods for Determining Gas Phase Stabilities by CID: Alkali Metal Complexes of Polyether Ionophore Antibiotics
}

\author{
Matthew W. Forbes and Dietrich A. Volmer \\ Institute for Marine Biosciences, National Research Council, Halifax, Nova Scotia, Canada
}

\section{Gregory J. Francis and Diethard K. Böhme}

Department of Chemistry, York University, Center for Research in Mass Spectrometry, Toronto, Ontario, Canada

\begin{abstract}
The gas phase stabilities of Group I metal complexes of the polyether ionophore antibiotics lasalocid and monensin were investigated by collision induced dissociation mass spectrometry. Electrospray ionization was used with a triple quadrupole mass spectrometer for the determination of threshold dissociation energies upon application of increasing collision energies. Various data analysis techniques for the determination of dissociation energies are discussed to assess the most suitable method for determining the stabilities of the ionophoremetal complexes studied here. In all cases only the relative stabilities of different complexes may be obtained by the method presented in this study, which does not assess absolute gas phase dissociation energies. Correction factors have been applied, however, to account for the energy conversion during collisions of different metal complexes and the varying degrees of freedom of different sized ligands, allowing for the comparison of the stabilities of different ionophores with like-metals. The measured threshold dissociation energies were compared with respect to the ionic radius of the metal cation, revealing a maximum stability for the $\mathrm{K}^{+}$ complexes of both lasalocid and monensin. A striking decrease in the stabilities of the $\mathrm{Rb}^{+}$and $\mathrm{Cs}^{+}$complexes was observed and is believed to be related to a decreasing degree of coordination that the ionophores can accomplish with the larger metals. (J Am Soc Mass Spectrom 2005, 16, 779-791) (c) 2005 American Society for Mass Spectrometry
\end{abstract}

$\mathrm{T}$ The polyether ionophores comprise a class of compounds first isolated from bacteria in the 1950s [1, 2] that has grown to consist of approximately 75 base molecules [3]. Of these base structures, thousands of active derivatives have been either isolated or synthesized. Yet all of the compounds owe their potent antimicrobial activity to the intrinsic affinity for cations, specifically the alkali metals that are biologically significant. The biological activity stems from their common ability to encapsulate metal cations by coordination via internal oxygen functional groups while maintaining a lipophilic outer surface of methyl and ethyl substitutents. For survival, bacteria maintain elevated concentrations of $\mathrm{Mg}^{2+}$ and $\mathrm{K}^{+}$inside the cell while selectively extruding $\mathrm{Ca}^{2+}$ and $\mathrm{Na}^{+}$[4]. Metal cations found in substantial abundance in aqueous biological environments are transported through lipid membranes only through the aid of active carrier proteins, without

Published online March 17, 2005

Address reprint requests to Dr. D. A. Volmer, Institute for Marine Biosciences, National Research Council, 1411 Oxford St., Halifax, Nova Scotia B3H 3Z1, Canada. E-mail: Dietrich.Volmer@nrc-cnrc.gc.ca which no trans-membrane movement would be possible. The antimicrobial properties of the ionophores are a result of their ability to move the otherwise insoluble cations through cell membranes, upsetting the natural cation gradient and ultimately causing cell death. Both gram-negative and gram-positive bacterial strains are sensitive to polyether ionophores; however, gram-positive species are typically more affected [5].

By the 1980s, the crystal structures and solution conformations of many ionophores had been well established by X-ray crystallography [6] and NMR techniques [7-12], respectively. It was shown that both in solution and in crystalline form, the ionophores favor a cyclic conformation, initiated by complexation with a cation. In addition, the antibiotics also contain a carboxylic functional group at one end of the molecule and can very often form intramolecular bonds to further facilitate and strengthen the cyclic structure. Computational studies have been widely applied to further elucidate the conformation and stabilities of ionophores both in solution [13,14] and the gas phase [15]. The structures of two of the most commonly used ionophores, lasalocid A (Las) and monensin A (Mon), are depicted in 
Scheme 1. The internal oxygen atoms have been shown to be arranged in a distorted octahedral coordination about the central $\mathrm{Na}^{+}$.

The binding stabilities and selectivities for different metals have been investigated extensively by potentiometric techniques [16-25]. Numerous ion transport studies have also been reported, discussing the relative metal-transport abilities of the various antibiotics to biological membranes [26, 27]. Polyether ionophores have found their most common use in the agricultural sector as anticoccidiostats in poultry as well as growth promoters in ruminant animals [28]. Their widespread production and sale as feed additives has prompted interest in monitoring the increase in microbial resistance in both humans and livestock [5]. There is also concern regarding the allowable residual levels found in dairy, poultry and beef products.

As a result, considerable efforts have been undertaken in recent years to develop accurate and sensitive methods for the characterization and quantitation of ionophores. Because of their polarity, high performance liquid chromatography (HPLC) methods are used in quantitative assays. Detection has been achieved by mass spectrometry coupled to various ion sources including electrospray ionization (ESI) [29-34], chemical ionization (CI) [35] fast atom bombardment (FAB) [36] and matrix assisted laser desorption ionization (MALDI) [37]. In addition to the development of analytical methods, numerous studies have described fragmentation mechanisms of ionophores using collision induced dissociation (CID) spectra. The sodium complexes of lasalocid [38] and monensin [39-43] have received considerable attention, as have salinomycin $[43,44]$ and tetronasin [45]. Furthermore, significant interest has been raised concerning the CID properties of different metal complexes with ionophores, including Group I, Group II, and several transition metals [46].

Recently, our group has prepared an account of the periodic nature of cation affinities for the ionophores lasalocid and monensin, in addition to investigating the metal-induced dissociation pathways of Group I complexes undergoing CID in a triple quadrupole (QqQ) mass spectrometer [47]. ${ }^{\circ}$ Complexes $^{\circ}$ of $^{\circ}$ monensin ${ }^{\circ}$ and lasalocid with $\mathrm{Li}, \mathrm{Na}, \mathrm{K}, \mathrm{Rb}$, and $\mathrm{C}$ s were prepared in methanolic solution, and the relative gas-phase affinities of the different cations were measured by comparing the onset energies of the free metal. A clear linear relationship was shown to exist between cationic radius and the metal affinity for the antibiotics. In this study, as opposed to determining the metal affinity for lasalocid and monensin, the relative gas phase stabilities of Group I complexes are investigated by examining the threshold dissociation energies of the complexes undergoing CID.

The determination of gas phase stabilities of ionic species has been accomplished by a variety of methods including infrared multi-photon dissociation (IRMPD), blackbody infrared radiative dissociation (BIRD), and CID. The common principle on which each method is based is that the vibrational or internal energy of the ion (a) Lasalocid. $\mathrm{Na}$

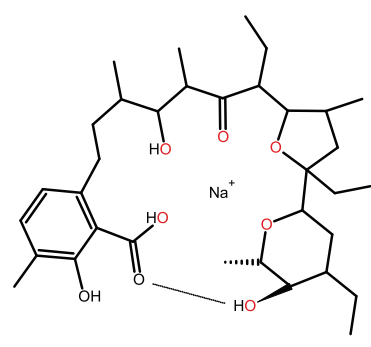

(b) Monensin $\cdot \mathrm{Na}$

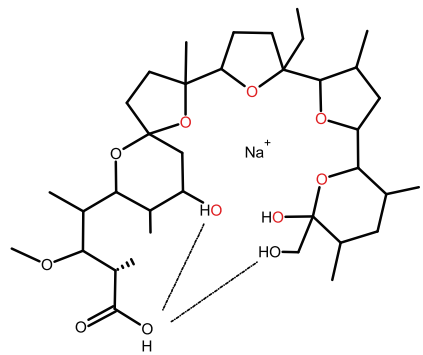

Scheme 1. (a) Las $\cdot \mathrm{Na}^{+}$and (b) Mon $\cdot \mathrm{Na}^{+}$showing the cyclic nature of the molecular conformation when complexed with a central metal cation. The hydrogen boding believed to strengthen the head-to-tail cycle is also indicated.

can be systematically increased by either the absorption of radiative energy or the conversion of translational energy to internal energy via collisions. With each method the analyst is charged with developing a criterion by which the threshold dissociation energy is defined in order to assign relative stabilities to the various species under investigation. In this study, gas phase stabilities of the various ionophore-metal complexes were determined by performing collision energy ramping experiments in a QqQ instrument and analyzing the data using a method suitable for the ionophoremetal complexes investigated here.

\section{Experimental}

\section{Chemicals}

Sodium salts of lasalocid and monensin were acquired from Sigma-Aldrich (Mississauga, ON, Canada) as were the acetate salts of $\mathrm{Li}, \mathrm{Na}, \mathrm{K}, \mathrm{Rb}$, and $\mathrm{Cs}$ and HPLCgrade methanol.

\section{Sample Preparation}

One $\mathrm{mg} \cdot \mathrm{mL}^{-1}$ stock solutions of the ionophores were prepared in methanol and stored at $4{ }^{\circ} \mathrm{C}$. Serial dilutions of the stock solutions were made to prepare samples at suitable concentrations for infusion into the mass spectrometer. Simultaneously, appropriate quantities of $20 \mathrm{mM}$ stock solutions (in $\mathrm{H}_{2} \mathrm{O}$ ) of each of the metal salts were added to the ionophoric solutions to give final concentrations of $0.1 \mu \mathrm{g} \cdot \mathrm{mL}^{-1}$ for each of the antibiotics with corresponding 10-fold molar excesses of each of the metals. The final compositions of the solutions were approximately $1 \% \mathrm{H}_{2} \mathrm{O}$ in methanol, serving to normalize any variations in hydration of the methanol from atmospheric or preparatory contamination. In many cases, a much lower concentration of the metal salt was required to obtain a strong signal than was used. However, the larger metals have lower binding constants than sodium (present in the reagents at substantial levels) so a significant excess must be added. 


\section{Instrumentation}

Collision energy ramping experiments (discussed below) were performed using an API 4000 triple quadrupole mass spectrometer (MDS Sciex, Concord, ON, Canada) equipped with a turbo ionspray source. Data acquisition methods were optimized for the sodium salts of the two ionophores utilizing the following pertinent instrument settings.

Lasalocid. Curtain gas (20), drying gas (0), nebulizer (50), needle voltage $(5000 \mathrm{~V})$, temperature $\left(80^{\circ} \mathrm{C}\right)$, declustering potential $(80 \mathrm{~V})$.

Monensin. Curtain gas (20), drying gas (0), nebulizer (60), needle voltage $(5500 \mathrm{~V})$, temperature $\left(75^{\circ} \mathrm{C}\right)$, declustering potential $(100 \mathrm{~V})$.

Solutions were introduced by direct infusion into the ion source at a flow rate of $5 \mu \mathrm{L} \cdot \mathrm{min}^{-1}$. MS ${ }^{n}$ experiments $(n=1$ to 5$)$ were conducted using an Agilent (Palo Alto, CA) 1100 Series LC/MSD SL quadrupole ion trap equipped with a low-flow ESI source. The same solutions from above were infused at a rate of $5 \mu \mathrm{L} \cdot \mathrm{min}^{-1}$.

The precursor ions were preselected in $\mathrm{Q}_{1}$ and subjected to progressively more energetic collisions in $q_{2}$ while several fragment ions were monitored in $Q_{3}$. The collision energy was controlled by varying the potential difference of the inter-quadrupole lens voltages between $q_{0}$ and $q_{2}$ in the range 5-130 V. As will be discussed below, ionophore-metal complexes are known to exhibit numerous fragmentation pathways including small neutral losses of $\mathrm{H}_{2} \mathrm{O}$ at lower collision energy, cleavages of the "backbone" of the macro-cycle at medium collision energies, and finally expulsion of the free metal cation beyond an intrinsic threshold energy for each specific complex. Replicates of the collision energy ramping experiments were performed in quintuplicate by recording transitions of the precursor ion to the characteristic fragment ions of each species in multiple reaction monitoring (MRM) mode. Typically, three to five fragment species were monitored (depending upon the degree of fragment variety arising from different metals), including the free metal cation and any precursor ions surviving transmission through the collision cell.

\section{CID Spectra and Energy Conversion}

To date, descriptions of fragmentation mechanisms combined with accurate mass assignments to product ions in CID spectra have primarily focused upon the sodiated ionophoric species, given that the sodium complexes are the predominant species observed in ESI spectra from both analytical standards and biological extracts. A summary of the commonly observed fragment ions arising from complexes with different metals has appeared in the literature and a qualitative explanation of the relative intensities observed in ESI spectra was ${ }^{\circ}$ offered ${ }^{\circ}$ by ${ }^{\circ}$ Shen ${ }^{\circ}$ and ${ }^{\circ}$ Brodbelt ${ }^{\circ}[46] .{ }^{\circ}$ Additionally, in their study, the genealogy of the fragmentation pathways of sodiated lasalocid and monensin were elucidated using double-resonance stored-waveform inverse Fourier transform (SWIFT) experiments. Recently, Lopes et al. reported detailed assignments of fragment ions observed for $\mathrm{Ag}^{+}, \mathrm{Ca}^{2+}$, and $\mathrm{Ba}^{2+}$ complexes of monensin that closely resembled the sodium analog [48]. ${ }^{\circ}$ The ${ }^{\circ}$ authors ${ }^{\circ}$ also ${ }^{\circ}$ observed ${ }^{\circ}$ several ${ }^{\circ}$ new ${ }^{\circ}$ fragments following CID of [Mon $\left.-\mathrm{H}^{+}+\mathrm{Cu}^{2+}\right]^{+}$that did not follow the same pathways as have been described for the other complexes: one being hydride abstraction by $\mathrm{Cu}^{2+}$ and the other involving reduction of $\mathrm{Cu}^{2+}$ to $\mathrm{a}$ $\mathrm{Cu}^{+}$species.

The first complete account of CID analysis of ionophores $^{\circ}$ was $^{\circ}$ presented $^{\circ}$ by $^{\circ} \mathrm{Kim}^{\circ}$ et. $^{\circ}$ al. ${ }^{\circ}[36] .{ }^{\circ}$ The ${ }^{\circ}$ authors describe a system of classifying two types of fragment ions, A-type and F-type. In general, A-type ions of ionophore-metal complexes comprise the metal cation bound to some fragment with the terminal carboxyl group, whereas F-type ions contain the metal cation and a terminal hydroxyl group. In addition to the $\mathrm{C}-\mathrm{C}$ bond cleavages giving rise to the A- and F-type fragments, the ionophores are also well known to undergo multiple losses of $\mathrm{H}_{2} \mathrm{O}$. The number and intensities of these fragments are thought to be charge-remote induce $^{\circ}$ processes $^{\circ}[49]^{\circ}$ that $^{\circ}$ may $^{\circ}$ give $^{\circ}$ some $^{\circ}$ indication ${ }^{\circ}$ of the resilience of the "backbone" structure of the molecule resulting from more stable gas phase geometries when the ionophore is coordinated to a suitable metal. In developing the relative abundance curves, the F-ion, the A-ion, and the free metal were monitored.

The fragmentation pathways of the sodium complex of lasalocid $(\mathrm{m} / \mathrm{z} 613)$ are given in Scheme 2. In addition to the A- $(\mathrm{m} / \mathrm{z} 359)$ and F-fragments $(\mathrm{m} / \mathrm{z} 377)$, three water losses were observed in the CID analysis at $\mathrm{m} / \mathrm{z}$ $595,{ }^{\circ} 577,{ }^{\circ}$ and $^{\circ} 559^{\circ}\left(\right.$ Figure $\left.^{\circ} 1\right) .^{\circ} \mathrm{A}^{\circ}$ closer $^{\circ}$ look $^{\circ}$ at ${ }^{\circ}$ the structure of lasalocid, however, does not reveal easily which portions of the molecule give rise to the observed water losses. To isolate the water losses, $\mathrm{MS}^{n}$ was performed using a quadrupole ion trap. The individual water-loss fragments were isolated and submitted to resonance excitation, yielding intact backbone complexes of lasalocid undergoing four consecutive water losses, the last of which was not observed in the CID spectrum $^{\circ}$ from $^{\circ}$ the ${ }^{\circ}$ triple $^{\circ}$ quadrupole. ${ }^{\circ}$ Figure $^{\circ} 1^{\circ}$ also shows product ion spectra of Las $\mathrm{K}^{+}$, Las $\cdot \mathrm{Rb}^{+}$, and Las. $\mathrm{Cs}^{+}$at the same collision energy showing the effect of the metal on the degree of fragmentation of the different complexes.

Analogous fragmentation pathways were observed for monensin. The sodium complex $(\mathrm{m} / \mathrm{z} 693)$ exhibits at least three significant backbone cleavages to yield Ftype ions at $m / z$ 617, 501, and 479. As with Las: $\mathrm{Na}^{+}$, three water losses were observed for Mon $\cdot \mathrm{Na}^{+}$, the first two of which are highly abundant in the product ion spectrum, the third being less so. 

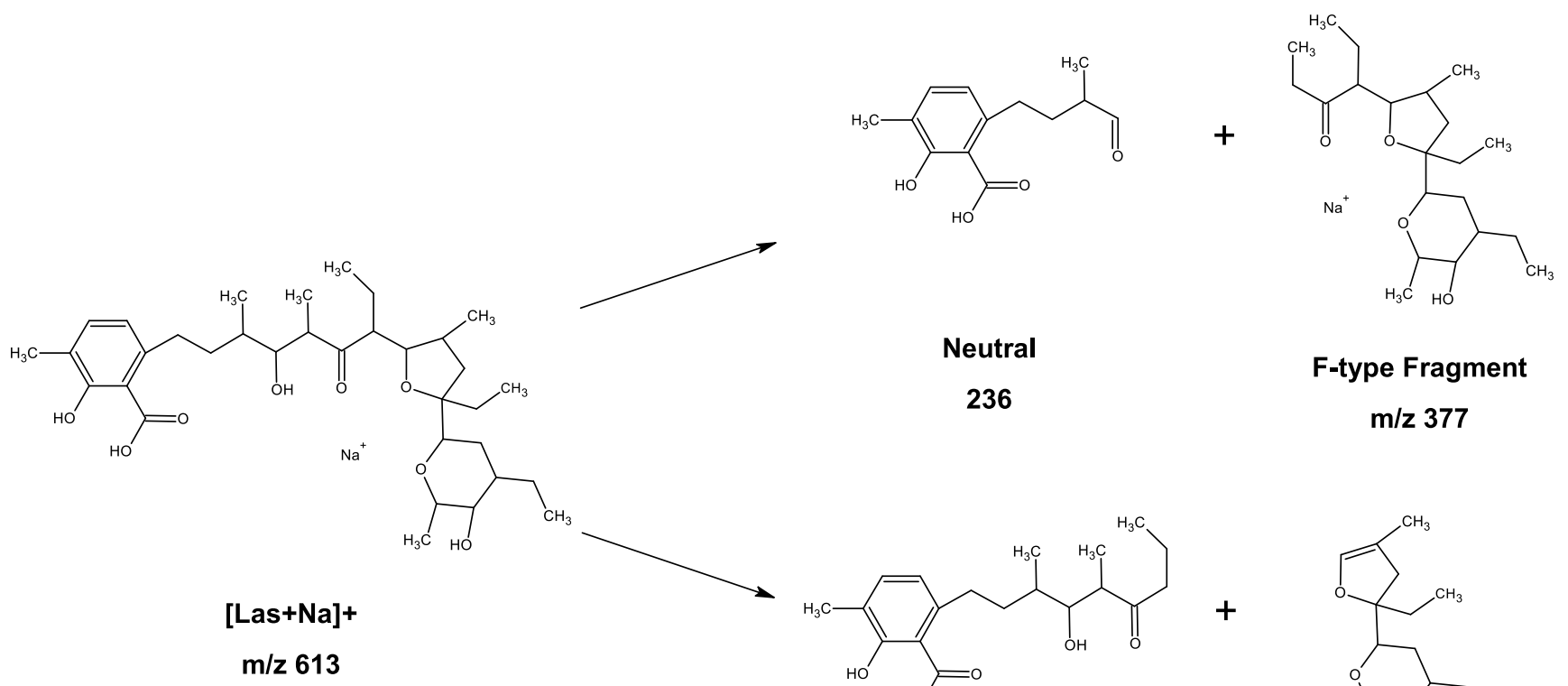

Neutral

236

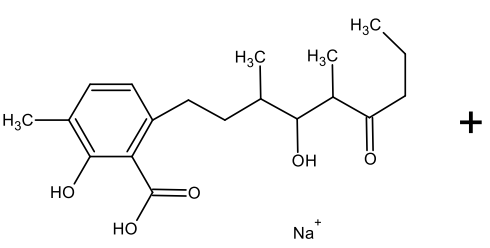

A-type Fragment

$\mathrm{m} / \mathrm{z} 359$
F-type Fragment

$\mathrm{m} / \mathrm{z} 377$

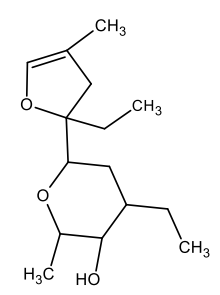

Neutral

Scheme 2. Fragmentation pathways of lasalocid showing formation of A- and F-type fragment ions.

Having defined species of interest to be investigated by the CID experiments, a further consideration must be made regarding how collisional energy is converted into vibrational energy, if the relative stabilities of ionophore-metal complexes are to be compared. Two main adjustments are widely applied to the laboratory frame collision energies $\left(E_{\text {lab }}\right)$. Following a collision event, only a fraction of the laboratory frame potential energy is actually converted to internal energy. In addition, the masses of the ion and the neutral also affect the conversion of collision energy. Eq 1 describes the maximum fraction $(f)$ of energy available to be

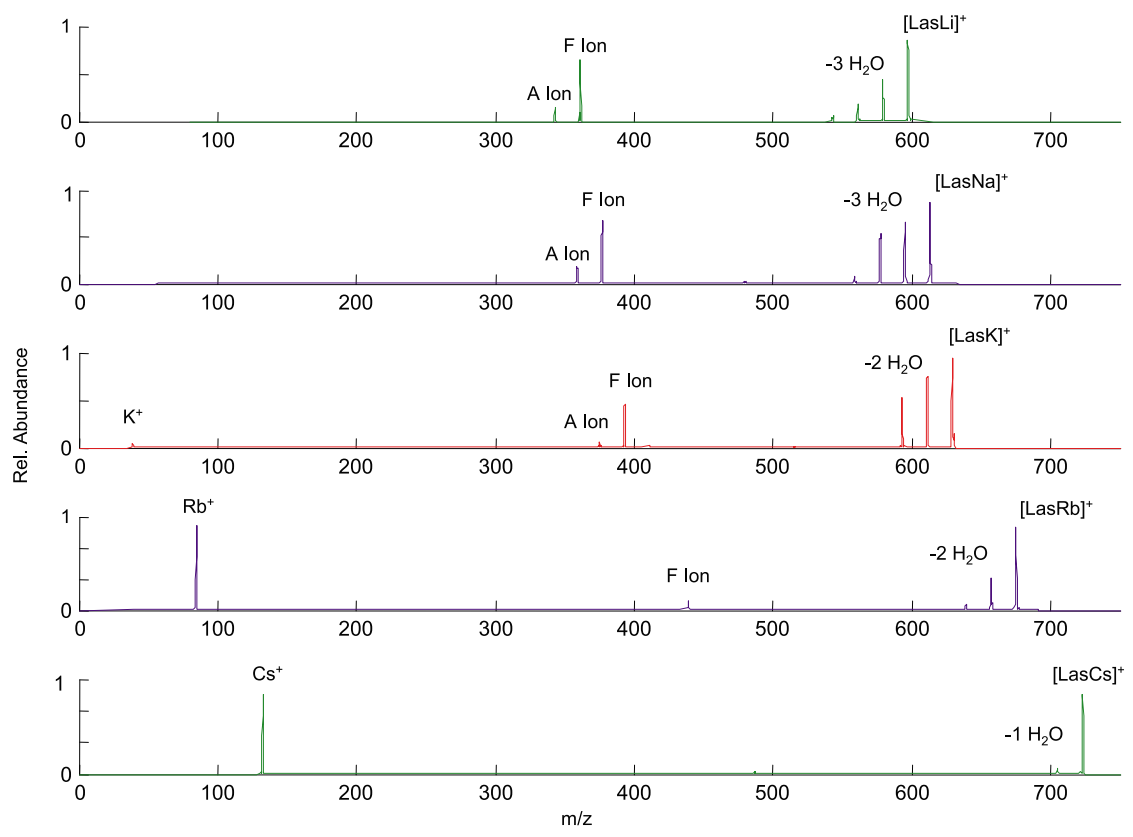

Figure 1. Product ion CID spectra of $[\mathrm{Las} \cdot \mathrm{Li}]^{+},[\mathrm{Las} \cdot \mathrm{Na}]^{+},[\mathrm{Las} \cdot \mathrm{K}]^{+},[\mathrm{Las} \cdot \mathrm{Rb}]^{+}$and $[\mathrm{Las} \cdot \mathrm{Cs}]^{+}$at $E_{\mathrm{Lab}}$ $\approx 40 \mathrm{~V}$ showing the relative abundance of the fragmentation routes of the complexes. 
converted as a function of $m_{n}$ and $m_{\text {ion }}$, the masses of the neutral collision gas and the precursor ion, respectively [50]:

$$
f=\frac{m_{n}}{m_{n}+m_{\text {ion }}}
$$

The relationship indicates that more massive ions will have less internal energy transferred than lighter ions. Thus, in order to compare stabilities of complexes with different metals, a correction factor $(\mu)$ must be applied and is defined as the ratio of energy conversion fractions for the species of interest and a reference compound.

$$
\mu=\frac{f_{\text {complex }}}{f_{\text {reference }}}
$$

In this case, the lightest of the complexes investigated is Las $\cdot \mathrm{Li}^{+}\left(m_{\text {ion }}=597 \mathrm{Da}\right)$ and will be defined as the reference complex. Thus, $\mu_{\text {LasLi }}=1.00$ and the laboratory frame collision voltages of the other complexes will be adjusted according to eqs 1 and 2. Applying the correction factor $(\mu)$ allows the comparison of collision energies from instruments using different collision gases and represents the maximum fraction of the laboratory energy that can be converted to internal energy. The correction factor applied here is not intended to represent an estimate of the actual quantity of translational energy converted to internal energy since eq 1 is overly simplistic and for which more rigorous models have been discussed at length in the literature [51]. ${ }^{\circ}$ Most $^{\circ}$ importantly, $^{\circ}$ for ${ }^{\circ}$ the ${ }^{\circ}$ assignment ${ }^{\circ}$ of ${ }^{\circ}$ relative dissociation energies, the mass correction is employed to take into account the differences in the energy conversion between ionophores of different masses or those bound to different metals. For example, if we consider the heaviest and the lightest Group I metals examined in this study, the more massive Cs complex will have a lower effective transfer of energy from a collision than the analogous Li complex. In the case of Las. $\mathrm{Li}^{+}$and Las. $\mathrm{Cs}^{+}$in collision with $\mathrm{N}_{2}$, the maximum possible energy conversions are approximately 2.3 and $1.9 \%$ of the laboratory collision energy, respectively. Although small, the differences are not insignificant and should not be neglected.

A second adjustment that has been made was de-

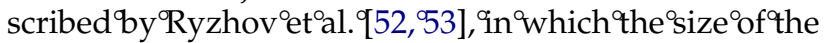
complex undergoing CID is taken into account to reflect the quantity of collisional energy converted to internal energy. Following a collision event, an ergodic process takes place where the energy deposited in the ion is distributed rapidly and evenly among all of the bonds. The average vibrational energy of a single bond resulting from a given collision will decrease when more bonds are available. The number of degrees of freedom $(D O F)$ of a system may be calculated from eq 3 , where $N$ is the number of atoms in the ionophore.

$$
\begin{aligned}
& D O F=3 N-6 \\
& \delta=\frac{D O F_{\text {ref }}}{D O F_{\text {complex }}}
\end{aligned}
$$

A correction factor $(\delta)$ can then be calculated for different complexes with respect to the number of degrees of freedom for a reference complex. In this study, lasalocid is the smaller of the two ionophore so it was selected as the reference compound.

$$
\begin{gathered}
\delta_{\text {Las }}=\frac{D O F_{\text {Las }}}{D O F_{\text {Las }}}=1 \\
\delta_{\text {Mon }}=\frac{D O F_{\text {Las }}}{D O F_{\text {Mon }}}=\frac{(3.97)-6}{(3.110)-6}=0.88
\end{gathered}
$$

When the correction factor is calculated for complexes of monensin, the laboratory collision energy will be reduced to the effective collision energy by a factor $\delta_{\text {Mon }}=0.88$, appropriate for the DOF of monensin. It follows that threshold dissociation energies $\left(E_{D}\right)$ calculated for like-metal complexes of lasalocid and monensin may be compared when the correction factor for degrees of freedom is applied.

\section{Data Analysis}

Herein is presented a summary of different methods by which threshold dissociation energies have been determined, particularly for noncovalent complexes, and a discussion of the suitability of these methods for the ionophore-metal complexes of interest to us. The ultimate goal of the experiments was to develop a systematic means whereby the relative gas phase stabilities of the various metal complexes can be assigned. The basic process that is being observed is the decomposition of a precursor ion complex following CID. By tracking the relative abundance of the precursor with respect to increasing collision energy, differences in the stabilities of the various metal complexes may be evaluated. Breakdown plots of the abundances of the ion species recorded in the multiple reaction monitoring (MRM) mode of the QqQ experiments were constructed with respect to collision energy. By means of various data analysis techniques, the stabilities of the ionophoremetal complexes were determined. Specifically, it is the threshold dissociation voltage $\left(E_{D}\right)$ that was measured as a function of the laboratory collision voltage. Therefore, we must select a set of criteria that, when applied consistently to the data sets, will yield a chemically relevant value for the threshold dissociation energy of the complex. The following sections briefly summarize previously developed conventions for the determination of dissociation energies of other host-guest systems and describe the application of each method to the dissociation curves of the ionophore-metal complexes. In each case the results have been examined to evaluate 
the suitability of the definition of the threshold dissociation energy.

\section{$E_{1 / 2}$ Method}

The first method for determination of threshold dissociation energy was recently described by Brodbelt and coworkers for analysis of host-guest systems of crown ethers ${ }^{\circ}$ and ${ }^{\circ}$ several $^{\circ}$ amine $^{\circ}$ compounds $^{\circ}[54]^{\circ} .{ }^{\circ}$ The ${ }^{\circ}$ abundances of the crown-amine complexes were monitored and the dissociation energy was defined as the excitation amplitude corresponding to a $50 \%$ survival rate of the precursor complex. This method of analysis is illustrated in ${ }^{\circ}$ Figure $2 \mathrm{a}$, , using $^{\circ}$ data ${ }^{9}$ recorded ${ }^{\circ}$ for ${ }^{\circ}$ the $\mathrm{CID}$ dissociation of the Las $\cdot \mathrm{Rb}^{+}$complex in the triple quadrupole MS.

A variation of the $E_{1 / 2}$ method was described by Ryzhov $^{\circ}$ et $^{\circ}{ }^{\circ} .^{\circ}\left[52{ }^{\circ},{ }^{\circ}{ }^{\circ}{ }^{\circ}\right.$ which ${ }^{\circ}$ the ${ }^{\circ}$ dissociation $^{\circ}$ energies $^{\circ}$ of Heme complexes with small peptides were evaluated. In virtually identical experiments as those conducted by Brodbelt et al., the appearance of the $[\mathrm{Heme}]^{+}$ion was monitored simultaneously with the decomposition of the Heme-peptide complex. The difference between the two studies lies in the analysis of the $E_{1 / 2}$ energy; whereas Brodbelt et al. defined the dissociation energy at $50 \%$ abundance ${ }^{\circ}$ of ${ }^{\circ}$ the ${ }^{\circ}$ precursor $^{\circ}$ complex $^{\circ}$ (Figure $\left.2 \mathrm{a}\right)$, ${ }^{\circ}$ Ryzhov et al. characterized the $E_{1 / 2}$ value as the collision energy at which the abundances of the precursor ion and the fragment ion were equal. A graphical analysis of the same Las $\cdot \mathrm{Rb}^{+}$complex $^{\circ}$ appears ${ }^{\circ}$ in $^{\circ}$ Figure $^{\circ} 2 \mathrm{~b}^{\circ}$ and $^{\circ}$ yields $^{\circ} \mathrm{a}$ slightly, though not insignificantly, higher value for $E_{D}$.

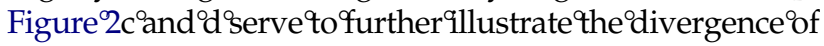
the values that are obtained applying the $E_{1 / 2}$ methods when Las. $\mathrm{K}^{+}$and Las. $\mathrm{Na}^{+}$are examined.

For clarification, Ryzhov et al. point out in their study that solitary [Heme $]^{+}$fragment ions are obtained for virtually all of the different peptide complexes, providing justification for the $E_{1 / 2}$ method. However, Figure ${ }^{\circ} 2^{\circ}$ does ${ }^{\circ}$ illustrate ${ }^{\circ}$ that ${ }^{\circ}$ the ${ }^{\circ}$ ionophore-metal ${ }^{\circ} \mathrm{Com}$ plexes may not be suitable candidates for analysis in the same way. As a result of significant alternate fragmentation pathways exhibited by ionophore complexes, such as the loss of 236 Da observed for lasalocid (Scheme 1), the disappearance of the Las $\cdot \mathrm{Metal}^{+}$species does not necessarily proceed directly via expulsion of the metal ion. The onset of the metal cation is indicative of the affinity of the metal for an intermediate species and it is not explicitly related to the gas phase stability of the ionophore-metal complex.

\section{Tangent Method}

In a previous paper, we have described measurement of the onset energies of metal cations from ionophoremetal $^{\circ}$ complexes $^{\circ}[47]^{\circ}{ }^{\circ}$ From $^{\circ}$ similar $^{\circ}$ experiments $^{\circ}$ to those ${ }^{\circ}$ presented ${ }^{\circ}$ in $^{\circ}$ Figure $^{\circ} 2,^{\circ}$ the ${ }^{\circ}$ portion ${ }^{\circ}$ of ${ }^{\circ}$ the ${ }^{\circ}$ disappearance curve where the abundance of the species is between 0.25 and 0.75 was analyzed. A least squares regression analysis was applied, yielding a regression
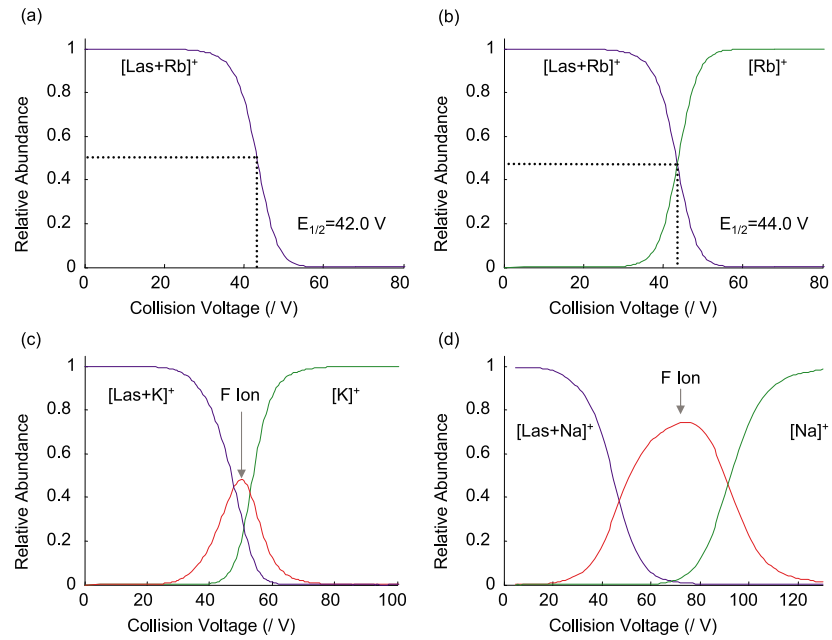

Figure 2. (a) Graphical representation of the determination of the dissociation energy by the $E_{1 / 2}$ method corresponding to the $50 \%$ abundance of the precursor Las $\mathrm{Rb}^{+}$complex. (b) Implementation of the $E_{1 / 2}$ method utilized by Ryzhov et al. for the same Las $\cdot \mathrm{Rb}^{+}$ complex whereby the dissociation energy is defined by the intersection of the disappearance and onset curves. (c) A species plot of the Las $\cdot \mathrm{K}^{+}$complex illustrating the further divergence of the two $\mathrm{E}_{1 / 2}$ methods used to evaluate the dissociation energy. (d) An example of the extreme case where the intersection of the disappearance and onset curves occurs at negligible relative abundance of both species.

line tangent to the linear portion of the curve where a rapid decrease in the abundance of the complex occurs. By extrapolation of the tangent line to the ordinate, a value for $E_{D}$ is $^{\circ}$ obtained ${ }^{\circ}$ as ${ }^{\circ}$ indicated ${ }^{\circ}{ }^{\circ}{ }^{\circ}$ Figure $^{\circ} 3$ a.

It ${ }^{\circ}$ becomes ${ }^{\circ}$ apparent, ${ }^{\circ}$ when ${ }^{\circ}$ Figure ${ }^{\circ} 3 b^{\circ}$ is ${ }^{\circ}$ scrutinized, that blindly applying the tangent method to multiple complexes may yield results that are misleading. First, with the exception of the Las. $\mathrm{Rb}^{+}$complex, all of the disappearance curves have fairly similar shapes and the tangent method yields consistent results for ranking $E_{D}$. The stability for the Group I complexes of lasalocid would be:

Cs $<\mathrm{Li}<\mathbf{R b}<\mathbf{N a}<\mathrm{K}$

This result is slightly different from the results that are obtained from the $E_{1 / 2}$ method ( $50 \%$ abundance) and close $^{\circ}$ examination ${ }^{\circ}$ of $^{\circ}$ Figure $^{\circ} 3 b^{\circ}$ reveals:

Cs $<\mathrm{Li}<\mathbf{N a}<\mathbf{R b}<\mathrm{K}$

Region $^{\circ} \mathrm{III}^{\circ}$ highlighted $^{\circ}$ in $^{\circ}$ Figure $^{\circ} 3 \mathrm{~b}^{\circ}$ illustrates $^{\circ}$ the discrepancy that occurs as a result of differences in the shapes of the curves. Although the abundance of the $\mathrm{Rb}$ complex remains higher prior to the region of the rapid decay, it is actually the magnitude of the slope of the decay curve that causes the tangent method to return a value that is lower; i.e., the regression line intersects the ordinate at lower collision energy than would be expected for one of the other complexes with a slope of lower magnitude. Regions I and II also point out intersections of other decay curves that may not necessarily affect the validity of the determination of dissociation energies but do serve to illustrate that the various complexes are undergoing different fragmenta- 
(a)

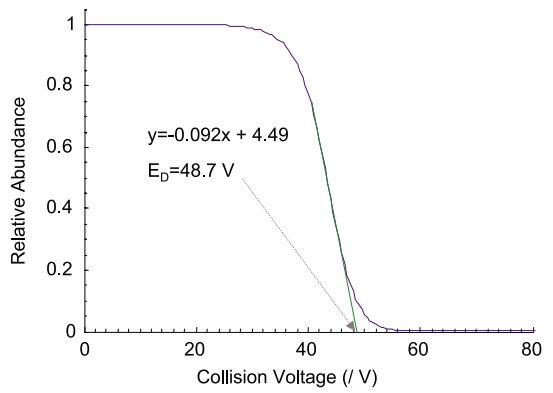

(b)

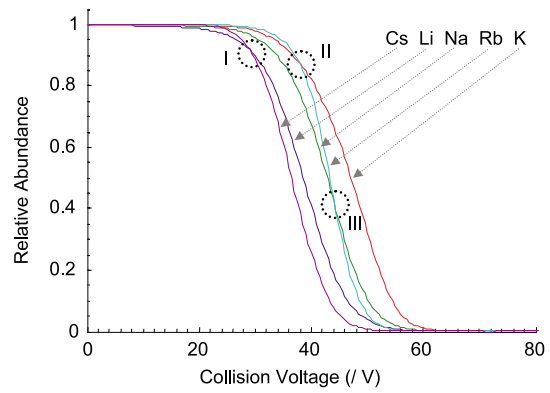

Figure 3. (a) Determination of $E_{D}$ for Las $\cdot \mathrm{Rb}^{+}$using the tangent method; the equation of the regression line was used to calculate the intercept of the ordinate. (b) Plots of the disappearance curves of the Group I complexes of lasalocid.

tion processes, or more precisely, are undergoing analogous fragmentation pathways in different proportions.

In real terms, this can be rationalized by an understanding of the fragmentation pathways available to ionophore ${ }^{\circ}$ complexes. Figure ${ }^{\circ}{ }^{\circ}$ shows ${ }^{\circ}$ production ${ }^{\circ}$ spectra of the $\mathrm{Na}$ and $\mathrm{Rb}$ complexes of lasalocid at a lab collision energy (CE) of $40 \mathrm{~V}$. Although there are neutral losses of water and a low intensity signal for an F-fragment from the Las. $\mathrm{Rb}^{+}$, the dominant pathway is the expulsion of the bare $\mathrm{Rb}^{+}$ion which becomes the sole mechanism at $C E>50 \mathrm{~V}$ and the abundance of the precursor Las $\cdot \mathrm{Rb}^{+}$is rapidly depleted. In contrast, the formation of $\mathrm{Na}^{+}$is not favored at $C E=40 \mathrm{~V}$ and does not become a dominant fragmentation mode until much higher collision energies $>100 \mathrm{~V}$. Thus, there are more alternate routes available to the Las $\cdot \mathrm{Na}^{+}$complex and the abundance of the precursor decays more slowly than its $\mathrm{Rb}$ counterpart. If strict adherence to the tangent method were applied, one would conclude that the $\mathrm{Rb}$ complex is significantly less stable than either the $\mathrm{Na}$ or $\mathrm{K}$ complexes, when in fact its decay curve shows that its relative abundance remains quite strong after the other complexes have begun to show reductions in abundance.

\section{Critical Slope Method}

A third means of analysis of the decay curves involves the use of a method that was originally developed for the determination of appearance potentials or ionization energies. Traditionally, the determination of ionization energies was carried out by irradiating gas phase species with a finely tuned, energy-resolved beam of electrons and monitoring, by mass spectrometry, the abundance of the molecular ion with respect to the ${ }^{\circ}$ energy ${ }^{\circ}$ of $^{\circ}$ the ${ }^{\circ}$ impinging ${ }^{\circ}$ electrons ${ }^{\circ}[50] .^{\circ} \mathrm{A}^{\circ}$ difficulty similar to that which we have faced in the analysis of the dissociation curves in these experiments was encountered by Honig when he analyzed the appearance potentials ${ }^{\circ}$ of ${ }^{\circ}$ ydrocarbons ${ }^{\circ}[55] .{ }^{\circ} \mathrm{A}^{\circ}$ thorough ${ }^{\circ}$ discussion of different methods used by his predecessors was presented in addition to a description of a scenario in which the tangent method provided erroneous results
[56]. ${ }^{\circ}{ }^{\circ}{ }^{\circ}$ response, ${ }^{\circ}$ Honig $^{\circ}$ suggested $^{\circ} a^{\circ}$ method ${ }^{\circ}$ whereby the appearance curves were replotted on a semi-logarithmic scale to better represent the exponential onset of the ${ }^{\circ}$ ionized $^{\circ}$ species. ${ }^{\circ}$ Figure $^{\circ} 4^{\circ}$ shows $^{\circ}$ an $^{\circ}$ example $^{\circ}$ of $^{\circ}$ a typical $^{\circ}$ onset $^{\circ}$ curve $^{\circ}$ plotted $^{\circ}$ in $^{\circ}$ both $^{\circ}$ linear $^{\circ}\left(\right.$ Figure $\left.^{\circ} 4 \mathrm{a}\right)$ and $^{\circ}$ semi-logarithmic $^{\circ}$ (Figure $\left.{ }^{\circ} 4 b\right)^{\circ}$ scales. $^{\circ}$ The $^{\circ}$ critical point $\left(E_{C}\right)$ is defined as the energy below which the onset of the ionic species is logarithmic (linear in a semi-log scale), that is, the energy beyond which the appearance of the ionic species no longer increases exponentially. This corresponds to the point on the appearance curve where the rate of change of the slope reaches a maximum and continues to decrease thereafter.

A direct comparison may be made between Honig's method applied to onset curves and the exponential decay curves of the precursor ionophore-metal complexes in this study. It is suggested that the point on the disappearance curve where the decay rate is no longer increasing (in other words, the point at which the rate of change of the slope reaches a minimum) would best measure, without bias, the threshold dissociation energy. Mathematically, this point is defined as the min-
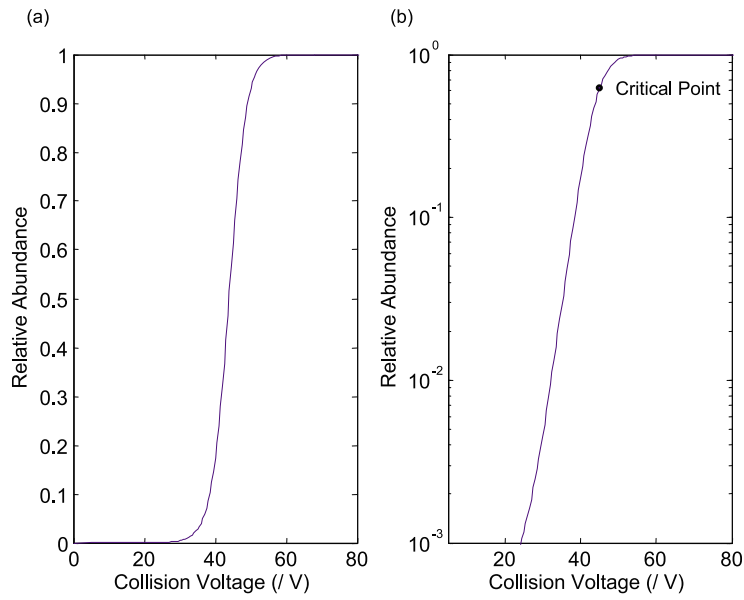

Figure 4. (a) Linear and (b) semi-log plots of an appearance curve. The critical point $\left(E_{C}\right)$ is indicated in plot $(\mathbf{b})$, corresponding to the voltage below which the curve is approximately linear. 
imum of the gradient function $d^{2} A / d E^{2}$, where $A$ is the abundance of the ionic species and $E$ is the collision energy.

To identify the threshold dissociation energies of the ionophore-metal complexes according to the definition described above (the point where the gradient is at a minimum), the data were processed by means of a digital filter using the software package Matlab (Mathworks, Mattick, MA). The filtering algorithm was written based upon a simplified least squares method to generate the second differential of the discrete data points from the dissociation curves. These methods, originally introduced to analytical chemists in 1964, have been widely applied to various data processing applications and have since become known as SG filters owing to the now-famous paper by Savitzgy and Golay in ${ }^{\circ}$ Analytical ${ }^{\circ} \mathrm{Chemistry}^{\circ}[57] . .^{\circ} \mathrm{A}^{\circ}$ detailed $^{\circ}$ discussion $^{\circ}$ of these methods will not be presented herein, however, the reader is directed to a tutorial on digital data filtering ${ }^{\circ}$ methods ${ }^{\circ}[58] .^{\circ}$ The $^{\circ}$ use $^{\circ}$ of $^{\circ}$ matrix ${ }^{\circ}$ algebraic methods by Matlab allows the calculation of differential functions for discrete data points with ease. In general, the algorithm examines a "window" of data points (the length of which can be specified) and returns the solution to the least squares, $n$th order polynomial linear regression. The solution is an $(n+1) x p$ matrix where $n$ is the order of the fitting equation and $p$ is the number of points. For example, a 2nd order SG filter fitting five moving points to the eq $f(x)=a+b x+c x^{2}$, has a least squares solution matrix (A) containing three rows of coefficients; the first row of the matrix contains the linear regression coefficients, the second row contains the first differential coefficients and the third row contains the second differential (gradient) coefficients.

$$
\begin{aligned}
& \mathrm{A}= \\
& {\left[\begin{array}{ccccc}
-0.0857 & 0.3429 & 0.4857 & 0.3429 & -0.0857 \\
-0.2000 & -0.1000 & 0 & 0.1000 & 0.2000 \\
0.1429 & -0.0714 & -0.1429 & -0.0714 & 0.1429
\end{array}\right]}
\end{aligned}
$$

The new filtered points are then calculated from the dot product of the third row of $\mathbf{A}\left(a_{3 n}\right)$ and the window of five points $\left(d_{i}\right)$ from the dissociation data. The calculation is carried out for every consecutive set of five points in the sliding window to generate a vector of filtered data, in this case the gradient. In general each filtered point $\left(p_{r}\right)$ is given by eq $7 \mathrm{a}$ and the filtered gradient vector $(\mathbf{G})$ is made up of the $N$ filtered points as in eq $7 b$.

$$
p_{r}=\left[\begin{array}{lllll}
a_{31} & a_{32} & a_{33} & a_{34} & a_{35}
\end{array}\right] \cdot\left[\begin{array}{c}
d_{i} \\
d_{i+1} \\
d_{i+2} \\
\vdots \\
d_{i+(p-1)}
\end{array}\right]
$$

Table 1. A summary of the laboratory dissociation voltage for the Las $\cdot \mathrm{K}^{+}$complex, as determined by both $E_{1 / 2}$ methods, the tanjent method and the critical slope method

\begin{tabular}{lccc}
\hline Critical slope & Tanjent & $E_{1 / 2}(50 \%)$ & $E_{1 / 2}$ (equal) \\
\hline \hline $45 \mathrm{~V}$ & $57 \mathrm{~V}$ & $48 \mathrm{~V}$ & $52 \mathrm{~V}$ \\
\hline
\end{tabular}

$$
G=\left[\begin{array}{c}
p_{\mathrm{r} 1} \\
p_{\mathrm{r} 2} \\
\vdots \\
p_{\mathrm{rN}}
\end{array}\right]
$$

It is pointed out that the solution matrix $\mathbf{A}$ is dependent only upon the order of the fitting equation and the number of points in the sliding window when the data are equally spaced. The filtered matrix $\mathbf{G}$, can then be calculated for numerous decomposition curves using the same coefficients for $\mathbf{A}$. In this way, the threshold dissociation energies were determined for each of the lasalocid and monensin metals complexes by calculation of the gradient curve and determination of the gradient minima for each complex. The methodology is best $^{\circ}$ summarized ${ }^{\circ}$ graphically $^{\circ}$ in $^{\circ}$ Figure $^{\circ} 5^{\circ}$ showing ${ }^{\circ}$ disappearance curves for the monensin-metal complexes and their associated gradient curves.

The comparison serves to point out two characteristics of the measurements; first, that the laboratory frame dissociation energies are not absolute and can be used only to assess the relative stabilities of the different metal $^{\circ}$ complexes. ${ }^{\circ}$ Table $^{\circ} 1$ summarizes the different laboratory dissociations voltages that one would obtain for the Las $\cdot \mathrm{K}^{+}$complex applying the four methods described above.
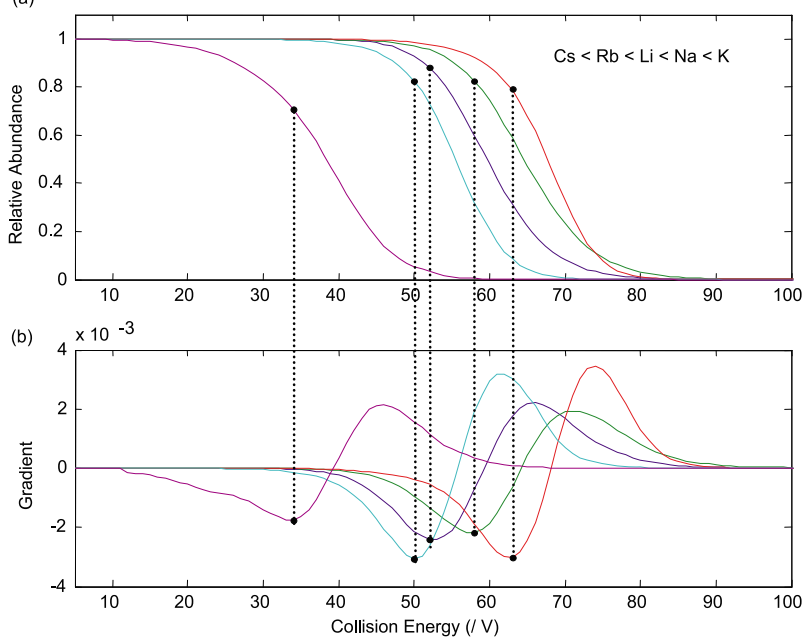

Figure 5. (a) Disappearance curves for monensin-metal complexes and (b) their associated gradient functions as determined using the SG digital filter. The minimum of the gradient function corresponds to the critical point on each disappearance curve at which the rate of dissociation of the complex is no longer exponential. This energy is defined as the threshold dissociation energy for the complex. 
Table 2. $\mathrm{A}^{\circ}$ summary ${ }^{\circ} \mathrm{f}^{\circ}$ dissociation voltages $\left(E_{D}\right)$ as determined by the critical slope method. The laboratory frame collision voltages are adjusted with scaling factors $(\mu)$ and $(\delta)$ to account for different masses and degrees of freedom of the various complexes upon conversion of translational energy to internal energy. The reference complex to which the correction factors are compared is $\mathrm{Las} \cdot \mathrm{Li}^{+}$, the smallest of the complexes investigated

\begin{tabular}{|c|c|c|c|c|c|c|c|c|}
\hline & \multicolumn{4}{|c|}{ Lasalocid } & \multicolumn{4}{|c|}{ Monensin } \\
\hline & $E_{L a b}(\mathrm{~V})$ & $\mu$ & $\delta$ & $E_{D}(\mathrm{~V})$ & $E_{L a b}(\mathrm{~V})$ & $\mu$ & $\delta$ & $E_{D}(\mathrm{~V})$ \\
\hline $\mathrm{Li}^{+}$ & 34 & 1.00 & 1 & 34 & 53 & 0.88 & 0.88 & 41 \\
\hline $\mathrm{Na}^{+}$ & 38 & 0.97 & 1 & 37 & 58 & 0.86 & 0.88 & 44 \\
\hline $\mathrm{K}^{+}$ & 45 & 0.95 & 1 & 43 & 63 & 0.85 & 0.88 & 47 \\
\hline $\mathrm{Rb}^{+}$ & 40 & 0.89 & 1 & 35 & 50 & 0.79 & 0.88 & 35 \\
\hline $\mathrm{Cs}^{+}$ & 31 & 0.83 & 1 & 26 & 34 & 0.75 & 0.88 & 22 \\
\hline
\end{tabular}

The impetus for selecting a particular method is based primarily upon the suitability of its application to the fragmentation pathways exhibited by the complex. The critical slope method is sensitive to the collision energy at which the disappearance of the parent complex is proceeding at the highest rate and thus takes into account the contributions of all of the significant fragmentation routes. Whereas the $E_{1 / 2}$ methods are primarily suited to systems that exhibit only one fragment ion, the tangent method has been shown to be of utility in disseminating appearance potentials when the shapes of the onset curves are all similar. However, the selection of any one method is based purely upon the differences in stabilities between complexes and not the magnitudes of the measurements. The critical slope method is the most appropriate for determination of dissociation energies of the ionophoremetal complexes, not because of the absolute values of the collision energies but because this method best reflects the nature of the decomposition of the various metal species.

Of additional interest is the application of the critical slope method to data from different CID conditions such as those encountered in quadrupole ion traps or Fourier transform ion cyclotron resonance mass spectrometers. As we have reported, different relative abundances of fragment ions have been observed for the ionophore-metal complexes in the QIT than were observed on the QqQ, resulting from differences in the frequency and energetics of $^{\circ}$ collision ${ }^{\circ}$ events. ${ }^{\circ}$ David ${ }^{\circ}$ and ${ }^{\circ}$ Brodbelt $^{\circ}$ reported ${ }^{\circ}[54]^{\circ}$ the determination of relative gas phase stabilities using CID by resonance excitation in a QIT in which the collision energy was reported as a function of the amplitude of the excitation potential. Under similar collision conditions, the differences in gas phase stabilities will still be apparent for different complexes and the threshold dissociation energies can be evaluated using the critical slope method. However, no experiments have been completed at this point to determine whether a different trend in stability for different complexes will be observed under different collision conditions. We do hypothesize that the threshold dissociation energy is an intrinsic property of the complex that should be unaffected by collision conditions.

\section{Results and Discussion}

Disappearance curves were constructed for the Group I complexes of lasalocid and monensin according to the experimental procedures described previously. Each curve was processed using a seven point, second order SG digital filter to generate the gradient functions. The collision voltages at the minimum of the second order differential curves were then identified as the critical points of the disappearance curves of each of the ionophore-metal ${ }^{\circ} \mathrm{Complexes}^{\circ}{ }^{\circ}$ Table ${ }^{\circ} 2$ summarizes all of the threshold stability energies determined via the critical point analysis of the decay curves for lasalocid and monensin. The correction factors for mass $(\mu)$ and degrees of freedom $(\delta)$ were applied to the laboratory collision voltages to obtain the scaled dissociation energies $\left(E_{D}\right)$.

The laboratory collision voltages also include uncertainties that are simply taken to be the increment by which the collision energy was stepped-in this case by $1 \mathrm{~V}$. The rationale for assigning $\pm 1 \mathrm{~V}$ was based upon the fact that the dissociation energy was defined from a point on the gradient curve and is a filtered representation of the abundance data recorded by the mass spectrometer. Thus, although the standard errors of abundance of five replicate experiments were determined to be only a fraction of a percent, a more rigorous condition was applied to estimate the uncertainty by saying that we could not be certain in the assignment of the threshold dissociation energy than being one of the points that were measured. This represents a relative uncertainty of 1-3\% (depending upon the magnitude of the laboratory voltage) and is considered reasonable despite being an over-estimate. The insignificant relative errors in the measured abundance and the reproducibility of the disappearance curves upon replication lend a good degree of confidence to the determinations of the relative stabilities of the ionophore metal complexes.

The first observation that can be made is based on a traditional means of comparison to another class of macro-cyclic ionophores, namely crown ethers that also show high tendencies to complex metal cations. It has long been established that there exists a strong relationship between the stability of crown ether-metal complexes $^{\circ}$ and $^{\circ}$ the $^{\circ}$ ionic $^{\circ}$ radius $^{\circ}$ of the $^{\circ}$ cation $^{\circ}[59]^{\circ},{ }^{\circ}$ and $^{\circ}$ in solution the stability series for $18-$ Crown- 6 bound to the alkali metals is:

$\mathrm{Li}<\mathrm{Na}<\mathrm{K} \gg \mathrm{Rb}>\mathrm{Cs}$

In the previous paper, where we investigated ${ }^{\circ}$ the 
Group I cation affinities for lasalocid and monensin, the appearance energies of the free metals were compared with respect to ionic radius revealing a negative correlation with increasing ionic radius as a result of polarizability effects. A similar comparison has ${ }^{\circ}$ been ${ }^{\circ}$ made $^{\circ}$ in $^{\circ}$ Figure $^{\circ} 6^{\circ}$ to investigate ${ }^{\circ}$ the ${ }^{\circ}$ relationship between cation size and the stability of the complex.

It $^{\circ}$ is ${ }^{\circ}$ clear $^{\circ}$ from ${ }^{\circ}$ Figure $^{\circ} 6^{\circ}$ that ${ }^{\circ}$ there ${ }^{\circ}$ is ${ }^{\circ} a^{\circ}$ different trend in the stabilities of the metal complexes than the linear trend that was observed for the metal affinities measured previously. Maximum stabilities were determined for the $\mathrm{K}^{+}$complexes of both Las and Mon and there appears to be a positive linear relationship of increasing stability with cation size through $\mathrm{Li}^{+}, \mathrm{Na}^{+}$, and $\mathrm{K}^{+}$. A sharp decline in stability occurs for both ionophores when the ionic radius reaches a threshold between $\mathrm{K}^{+}$and $\mathrm{Rb}^{+}$, at which point there appears to be an inverse dependence. These observations point to a phenomenon that can be explained by the degree of coordination that the ionophore is able to accomplish with cations of varying size. When the first shell coordination geometry most closely matches the conformation of the $\mathrm{O}$ atoms participating in coordination with the antibiotic, the most stable species is obtained. The same effect of cationic size, therefore, can be attributed to the antibiotic complexes as is known to exist for crown ethers.

It would also appear that the sharp decrease in threshold stability of the $\mathrm{Rb}^{+}$and $\mathrm{Cs}^{+}$points to a lesser degree of coordination interaction between the ionophore and the larger metals. It is not difficult to imagine that beyond a particular size, the ionophore is no longer able to "encapsulate" the metal but must take on a less favorable geometry, dominated primarily by electrostatic interaction. In addition, it may also be the case that the hydrogen bonding in the "headto-tail" conformation of the ionophore is interrupted beyond a critical diameter of the metal. However, it is found that this hypothesis is not supported upon examination of calculated structures. Juillard et al. $[11]^{\circ}$ discuss $^{\circ}$ detailed $^{\circ}$ in $^{\circ}$ vacuo $^{\circ}$ structure $^{\circ}$ of $^{\circ}$ metal complexes of lasalocid obtained by semi-empirical calculations, indicating that the cyclic structure remains intact by virtue of the fact that the internuclear $\mathrm{O}-\mathrm{H}$ hydrogen bonding distance between the head and the tail remained approximately the same for complexes of $\mathrm{Li}^{+}, \mathrm{Na}^{+}, \mathrm{K}^{+}, \mathrm{Rb}^{+}$, and $\mathrm{Cs}^{+}$.

The $\mathrm{MS}^{2}$ spectra of the progressively larger metal complexes that we observed, however, do not support this conclusion. It would appear that some change in molecular conformation takes place if we accept the differences in the threshold stability energies and must deviate from the ideal cyclic conformation for larger metals. Further support for this theory may be taken from the decrease in the relative abundance of the F-type ions observed in the product ion spectra as the metal size increases. Returning to Figure 1 , the Las $\cdot \mathrm{Na}^{+}{ }^{\circ}$ and ${ }^{\circ} \mathrm{Las} \cdot \mathrm{K}^{+}{ }^{\circ}$ complexes ${ }^{\circ}$ give rise to substantial signals for both A- and F-type ions, whereas Las $\cdot \mathrm{Rb}^{+}$shows a much lower abundance of the F-ion with the A-ion being absent altogether. Examination of the Las. $\mathrm{Cs}^{+}$product ion spectrum shows the abundance of the F-fragment further depressed to $<2 \%$ of the total abundance. If the gas phase complexes of the ionophores all have similar conformations and if all tend to coordinate the different metals to the same extent, as is suggested by the calculations, it would seem reasonable to expect

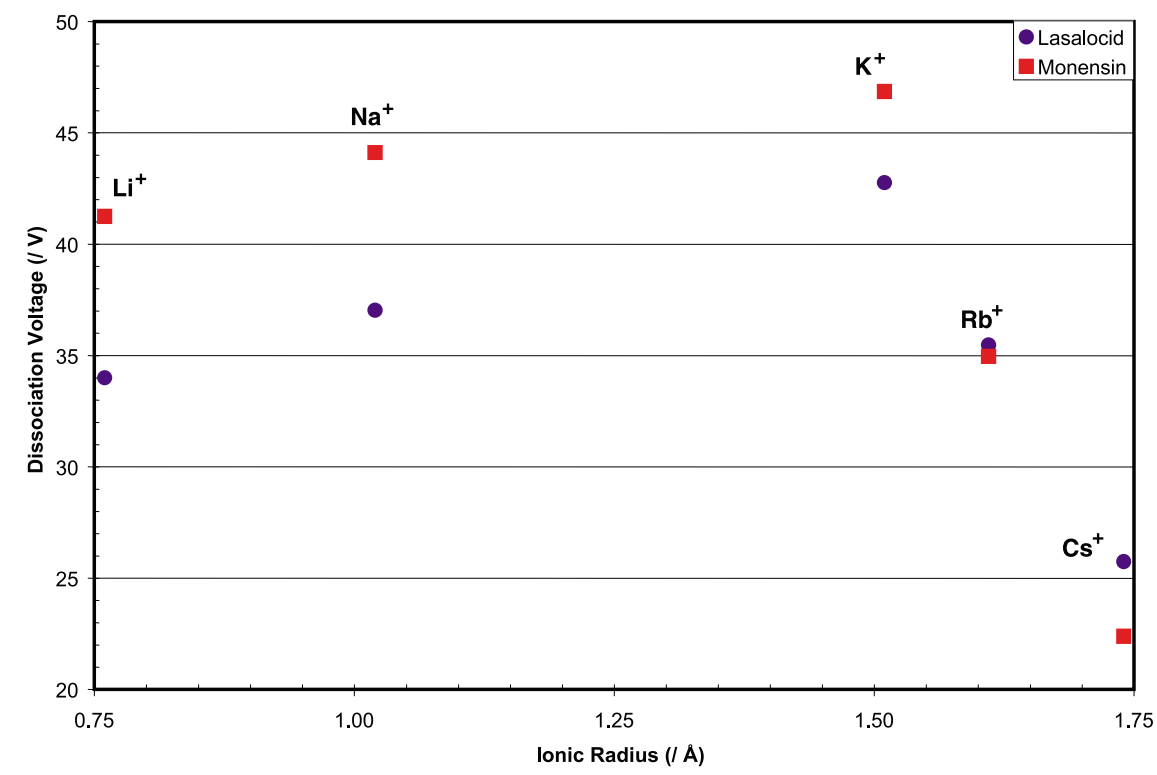

Figure 6. Plots of the stabilities of the Group I metal complexes of (filled circle) lasalocid and (filled

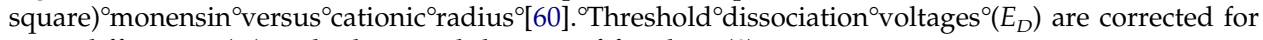
mass differences $(m)$ and vibrational degrees of freedom $(\delta)$. 
Table 3. Stability trends for the Group I metal complexes of lasalocid and monensin

\begin{tabular}{ll}
\hline Lasalocid & $\mathrm{Cs}<\mathrm{Li}<\mathrm{Rb}<\mathrm{Na}<\mathrm{K}$ \\
Monensin & $\mathrm{Cs}<\mathrm{Rb}<\mathrm{Li}<\mathrm{Na}<\mathrm{K}$ \\
\hline
\end{tabular}

that similar fragmentation pathways at similar threshold energies would be observed. In contrast, we suggest that the degree of coordination is interrupted by the large size of $\mathrm{Rb}^{+}$and $\mathrm{Cs}^{+}$, leading to a decrease in the gas phase stability.

One further piece of evidence supporting this hypothesis can be found in the convergence of the threshold dissociation energies for the $\mathrm{Rb}^{+}$and $\mathrm{Cs}^{+}$ complexes of lasalocid and monensin. Although the laboratory dissociation energies appear to be quite different, after applying correction factors for mass $(\mu)$ and degrees of freedom $(\delta)$, the normalized $E_{D}$ values are virtually identical for $L a s \cdot \mathrm{Rb}^{+}$and Mon $\cdot \mathrm{Rb}^{+}$and extremely close for Las. $\mathrm{Cs}^{+}$and Mon. $\mathrm{Cs}^{+}$. It would appear that the comparatively higher stability of the monensin complexes (resulting from better coordination geometries than are available to the lasalocid complexes) is diminished when the degree of coordination is reduced by the cation size. In effect, the remaining binding capability is largely electrostatic in nature and is unaided by the advantages of increased coordination.

\section{Conclusions}

The final stability trends for the Group I metals are given ${ }^{\circ}{ }^{\circ}$ Table $^{\circ} 3$. $^{\circ}$ The $^{\circ}$ marked $^{\circ}$ decrease $^{\circ}$ in ${ }^{\circ}$ the $^{\circ}$ stabilities of the $\mathrm{Rb}$ and $\mathrm{Cs}$ complexes is believed to be attributable to the marginal degree of coordination of the ionophore to the metal cation. Further studies are currently underway to extend the stability measurements for Group II cations and some transition metals to explore the interaction between charge density, cationic radius, and coordination geometry. The critical slope method developed here to extract threshold dissociation energies from disappearance curves should be applicable to a wide range of metal-ligand systems regardless of the dissociation pathways available to the system being studied. In particular, we plan to continue our investigations of some of the other commonly available ionophoric antibiotics.

\section{Acknowledgments}

The authors acknowledge financial support from the National Sciences and Engineering Research Council of Canada (NSERC) and MDS Sciex. They also thank Dr. Peter Wentzell (Dalhousie University, Halifax) for help with developing algorithms to perform digital filtering using Matlab.

\section{References}

1. Berger, J.; Rachlin, A. I.; Scott, W. E.; Sternbach, L. H.; Goldberg, M. W. The isolation of three new crystalline antibiotics from Streptomyces. J. Am. Chem. Soc. 1951, 73, 5295-5298.
2. Harned, R. L.; Hidy, P. H.; Corum, C. J.; Jones, K. L. Nigericin, a new crystalline antibiotic from an unidentified Streptomyces. Antibiot. Chemother. 1951, 1, 594-596.

3. Westley, J. W. Notation and classification. In Polyether antibiotics: Naturally occurring acid ionophores, Vol. 1; Westley, J. W., Ed.; Marcel Dekker, Inc.: New York, 1982; pp 1-20.

4. Westley, J. W. Chemical transformations. In Polyether antibiotics: Naturally occurring acid ionophores, Vol. 2; Westley, J. W., Ed.; Marcel Dekker, Inc: New York, 1983; pp 51-86.

5. Russell, J. B.; Houlihan, A. J. Ionophore resistance of ruminal bacteria and its potential impact on human health. FEMS Microbiol. Rev. 2003, 27, 65-74.

6. Duesler, E. N.; Paul, I. C. In X-ray structures of the polyether antibiotics, Vol. 2; Westley, J. W., Ed.; Marcel Dekker, Inc.: New York, 1983; p 415.

7. Anteunis, M. J. O. Structure, conformation, and mechanism of action as revealed by proton NMR. In Polyether antibiotics: Naturally occurring ionophores, 2; Westley, J. W., Ed.; Marcel Dekker, Inc.: New York, 1983; pp. 245-334.

8. Seto, H.; Otake, N. ${ }^{13} \mathrm{C}$ NMR spectra of polyether antibiotics. In Polyether antibiotics: Naturally occurring acid ionophores, Vol. 2; Westley, J. W., Ed.; Marcel Dekker, Inc.: New York, 1983; pp 335-400.

9. Lyazghi, R.; Cuer, A.; Dauphin, G.; Juillard, J. Interactions between metal cations and the ionophore lasalocid. Part 9. Structural study of the free acid, anion, and potassium complex salt chloroform and methanol using ${ }^{13} \mathrm{C}$ and ${ }^{1} \mathrm{H}$ NMR spectroscopy. J. Chem. Soc. Perkin. Trans. 2. 1992, 1, 35-42.

10. Mimouni, M.; Malfreyt, P.; Lyazghi, R.; Palma, M.; Pascal, Y.; Dauphin, G.; Juillard, J. Interactions between metal cations and the ionophore lasalocid. Part 13. Structure of 1:1 and 2:1 lasalocid anion-divalent cation complexes in methanol. J. Chem. Soc. Perkin. Trans. 2. 1995, 1939-1947.

11. Malfreyt, P.; Lyazghi, R.; Dauphin, G.; Pascal, Y.; Juillard, J. Interactions between metal cations and the ionophore lasalocid. Part 14. Structure of lasalocid-alkali metal cation complex salts in methanol from NMR spectroscopy and computational experiments. J. Chem. Soc. Perkin. Trans. 2. 1996, 1971-1979.

12. Mimouni, M.; Lyazghi, R.; Juillard, J. Formation and structure of alkali metal, thallium, silver, and alkaline-earth cation complexes with the ionophore lasalocid free acid form in methanol from NMR experiments. New J. Chem. 1998, 367-372.

13. Malfreyt, P.; Pascal, Y.; Juillard, J. Open and closed forms of the ionophore lasalocid free acid and free anion. Obtaining the most probable conformations using AM1 semi-empirical quantum mechanical calculations. J. Chem. Soc. Perkin. Trans. 2. 1994, 2031-2038.

14. Malfreyt, P.; Mimouni, M.; Pascal, Y.; Juillard, J. Structure and dynamics of the ionophore lasalocid. A multicomputational study. II. Methanol solutions. J. Chim. Phys. 1996, 93, 11511172 .

15. Malfreyt, P.; Pascal, Y.; Juillard, J. Structure and dynamics of the ionophore laslaocid. A multi-computational study. I. Gaseous state. J. Chim. Phys. 1996, 93, 1129-1150.

16. Bolte, J.; Demuynck, C.; Jeminet, G.; Juillard, J.; Tissier, C. Comparative study of three antibiotic ionophores: X537A (lasalocid), A23187 (calcimycin), and X14547A. Complexation with Group IA and IIA cations, calcium transport. Can. J. Chem. 1982, 60, 981-989.

17. Mimouni, M.; Pointud, Y.; Juillard, J. Interactions in methanol of divalent metal cations with bacterial ionophores, lasalocid, and monensin: Thermodynamic aspects. Bull. Soc. Chim. Fr. 1994, 131, 58-65.

18. Pointud, Y.; Astier, L.; Touzain, S.; Juillard, J. Thermodynamics of the formation of acid metal complexes of monensin and lasalocid in acetonitrile. Calorim. Anal. Therm. 1995, 26, 145149. 
19. Herbrant, M.; Lyazghi, R.; Pointud, Y.; Juillard, J. Alkali metal cation-bacterial ionophore interactions. An original method for determination of enthalpies of reactions in binary aqueous phase-organic phase systems by calorimetry. Calorim. Anal. Therm. 1990, 20/21, 41-47.

20. Juillard, J.; Tissier, C.; Jeminet, G. Interactions between metal cations and the ionophore lasalocid. Part 1. Complexation of alkaline-earth-metal cations by lasalocid, bromolasalocid, and salicylic acid in methanol. J. Chem. Soc. Faraday Trans. 1. 1988, 84, 951-958.

21. Pointud, Y.; Juillard, J. Interactions between metal cations and the ionophore lasalocid. Part 2. Gibbs functions, enthalpies, and entropies for complexation of alkali-metal cations by lasalocid and bromolasalocid. J. Chem. Soc. Faraday Trans. 1. 1988, 84, 959-967.

22. Laubry, P.; Tissier, C.; Mousset, G.; Juillard, J. Interactions between metal cations and the ionophore lasalocid. Part 3. Interactions of lasalocid with $\mathrm{Mn}^{2+}, \mathrm{Fe}^{2+}, \mathrm{Co}^{2+}, \mathrm{Ni}^{2+}$, and $\mathrm{Zn}^{2+}$ in methanol. J. Chem. Soc. Faraday Trans. 1. 1988, 84, 969-978.

23. Pointud, Y.; Passelaigue, E.; Juillard, J. Interactions between metal cations and the ionophore Lasalocid. Part 4. DH and DS for formation of 1-1 and 2-1 complexes of the lasalocid anion and salicylate with alkaline-earth metal cations in methanol. J. Chem. Soc. Faraday Trans. 1. 1988, 84, 1713-1722.

24. Laubry, P.; Mousset, G.; Martinet, P.; Tissier, M.; Tissier, C.; Juillard, J. Interactions between metal cations and the ionophore lasalocid. Part 5. A potentiometric, polarographic, and electron spin resonance study of copper(II)-lasalocid equilibria in methanol. J. Chem. Soc. Faraday Trans. 1. 1988, 84, 3175-3185.

25. Tissier, M.; Mousset, G.; Juillard, J. Interactions between metal cations and the ionophore lasalocid. Part 6. Potentiometric and electron spin resonance study of the complexation of $\mathrm{Gd}^{3+}$ in methanol by lasalocid and simpler carboxylic acids. J. Chem. Soc. Faraday Trans. 1. 1989, 85, 1337-1349.

26. Taylor, R. W. Kauffman, R. F.; Pfeiffer, D. R. Cation complexation and transport by carboxylic acid ionophores. In Polyether antibiotics: Naturally occurring ionophores, Vol. 1. Westley, J. W., Ed.; Marcel Dekker, Inc.: New York, 1982; pp 103-184.

27. Aouad, N.; Miquel-Mercier, G.; Bienvenue, E.; Tronel-Peyroz, E.; Jeminet, G.; Juillard, J.; Seta, P. Lasalocid (X537A) as a selective carrier for $\mathrm{Cd}(\mathrm{II})$ in supported liquid membranes. J. Membr. Sci. 1998, 139, 167-174.

28. Compendium of Medicating Ingredients Brochures; Government of Canada: 1998; MIB no. 57 1-8, no. 66 1-8.

29. Schneider, R. P.; Lynch, M. J.; Ericson, J. F.; Fouda, H. G. Electrospray ionization mass spectrometry of semduracmicin and other polyether ionophores. Anal. Chem. 1991, 63, 17891794.

30. Blanchflower, W. J.; Kennedy, D. G. Determination of lasalocid in eggs using liquid chromatography-electrospray mass spectrometry. Analyst 1995, 120, 1129-1132.

31. Blanchflower, W. J.; Kennedy, D. G. Determination of monensin, salinomycin, and narasin in muscle, liver, and eggs from domestic fowl using liquid chromatography-electrospray mass spectrometry. J. Chromatogr. B 1996, 675, 225-233.

32. Volmer, D. A.; Lock, C. M. Electrospray ionization and CID of antibiotic polyether ionophores. Rapid Commun. Mass Spectrom. 1998, 12, 157-164.

33. Harris, J. A.; Russell, C. A. L.; Wilkins, P. G.; The characterization of polyether ionophore veterinary drugs by HPLCelectrospray MS. Analyst 1998, 123, 2625-2628.

34. Matabudul, D. K.; Lumley, I. D.; Points, J. S. The determination of five anticoccidial drugs (nicarbazin, lasalocid, monensin, salinomycin, and narasin) in animal livers and eggs by liquid chromatography linked with tandem mass spectrometry. Analyst 2002, 127, 760-768.
35. Ramsey, E. D.; Berry, A. J.; Lawrence, S. D.; Games, D. E.; Startin, J. R. Ionophores: Potential screening via supercriticalfluid chromatography combined with mass spectrometry and tandem mass spectrometry. Rapid Commun. Mass Spectrom. 1995, 9, 712-716.

36. Kim, Y. H.; Yoo, J. S.; Lee, C. H.; Goo, Y. M.; Kim, M. S. Application of fast atom bombardment combined with tandem mass spectrometry to the structural elucidation of odemethylabierixin and related polyether antibiotics. J. Mass Spectrom. 1996, 31, 855-860.

37. Wang, J.; Sporns, P. MALDI-TOF MS quantification of coccidiostats in poultry feeds. J. Agric. Food Chem. 2000, 48, 28072811.

38. Lopes, N. P.; Gates, P. J.; Wilkins, J. P. G.; Staunton, J.; Fragmentation studies on lasalocid acid by accurate mass electrospray mass spectrometry. Analyst 2002, 127, 1224-1227.

39. Kiehl, D. E.; Julian, R. K.; Kennington, A. S. Electrospray ionization mass spectrometry with in-source collision induced dissociation of monensin factors and related metabolites. Rapid Commun. Mass Spectrom. 1998, 12, 903-910.

40. Lopes, N. P.; Stark, C. B. W.; Hong, H.; Gates, P. J.; Staunton, J. A study of the effect of $\mathrm{pH}$, solvent system, cone potential, and the addition of crown ethers on the formation of the monensin protonated parent ion in electrospray mass spectrometry. Analyst 2001, 126, 1630-1632.

41. Lopes, N. P.; Stark, C. B. W.; Gates, P. J.; Staunton, J. Fragmentation studies on monensin A by sequential electrospray mass spectrometry. Analyst 2002, 127, 503-506.

42. Lopes, N. P.; Stark, C. B. W.; Hong, H.; Gates, P. J.; Staunton, J. Fragmentation studies on monensin A and B by accuratemass electrospray tandem mass spectrometry. Rapid Commun. Mass Spectrom. 2002, 16, 414-420.

43. Miao, X.; March, R. E.; Metcalfe, C. D. Fragmentation study of salinomycin and monensin A antibiotics using electrospray quadrupole time-of-flight mass spectrometry. Rapid Commun. Mass Spectrom. 2003, 17, 149-154.

44. Davis, A. L.; Harris, J. A.; Russell, C. A. L.; Wilkins, J. P. G. Investigations by HPLC-electrospray mass spectrometry and NMR spectroscopy into the isomerization of salinomycin. Analyst 1999, 124, 251-256.

45. Fonseca, T.; Lopes, N. P.; Gates, J. P.; Staunton, J. Fragmentation studies on tetronasin by accurate-mass electrospray tandem mass spectrometry. J. Am. Soc. Mass Spectrom. 2004, 15, 325-335.

46. Shen, J.; Brodbelt, J. S. Characterization of ionophore-metal complexes by infrared multiphoton photodissociation and collision activated dissociation in a quadrupole ion trap mass spectrometer. Analyst 2000, 125, 641-650.

47. Francis, G. J.; Forbes, M. W.; Volmer, D. A.; Böhme D. K. Analyst 2005, in press.

48. Lopes, N. P.; Stark, C. B. W.; Staunton, J.; Gates, J. P. Evidence for gas-phase redox chemistry inducing novel fragmentation in a complex natural product. Org. Biomol. Chem. 2004, 2, 358-363.

49. Adams, J. Charge-remote fragmentations-Analytical applications and fundamental studies. Mass Spectrom. Rev. 1990, 9, 141-186.

50. Gross, J. H. In Mass Spectrometry: A Textbook; Gross, J. H., Ed.; Springer-Verlag: Berlin, Heidelberg, New York, 2004; p 55.

51. Shukla, A. K.; Futrell, J. H. Tandem mass spectrometry: Dissociation of ions by collisional activation. J. Mass Spectrom. 2000, 35, 1069-1090.

52. Jellen, E. E.; Chappell, A. M.; Ryzhov, V. Effects of size of noncovalent complexes on their stability during collisioninduced dissociation. Rapid Commun. Mass Spectrom. 2002, 16, 1799-1804. 
53. Hayes, L. A.; Chappell, A. M.; Jellen, E. E.; Ryzhov, V. Binding of metalloporphyrins to model nitrogen bases: Collision-induced dissociation and ion-molecule reactions studies. Int. J. Mass Spectrom. 2003, 227, 111-120.

54. David, W. M.; Brodbelt, J. S. Threshold dissociation energies of protonated amine/polyether complexes in a quadrupole ion trap. J. Am. Soc. Mass Spectrom. 2003, 14, 383-392.

55. Honig, R. E. Ionization potentials of hydrocarbons. J. Chem. Phys. 1947, 16, 105-112.

56. Stevenson, D. P.; Hipple, J. A. Ionization of argon and neon by electron impact. Phys. Rev. 1942, 62, 237-240.

57. Savitzky, A.; Golay, M. J. E. Smoothing and differentiation of data by simplified least squares procedures. Anal. Chem. 1964, $36,1627-1639$.

58. Wentzell, P. D.; Brown, C. D. Signal Processing in Analytical Chemistry. In Encyclopedia of Analytical Chemistry, Vol. XI; Meyers, R. A., Ed.; Wiley: Chichester, UK, 2000; pp $9764-9800$

59. Izatt, R. M.; Bradshaw, J. S.; Nielson, S. A.; Lamb, J. D.; Christensen, J. J. Thermodynamic and kinetic data for cationmacrocyle interaction. Chem. Rev. 1985, 85, 271-339.

60. Evans, H. T. Ionic radii in crystals. In CRC Handbook of Chemistry and Physics; Lide, D. R., Ed.; CRC Press: Boca Raton, 1995; pp 12-18. 